\title{
Presence of a vacuolar $\mathrm{H}^{+}$-pyrophosphatase in promastigotes of Leishmania donovani and its localization to a different compartment from the vacuolar $\mathrm{H}^{+}$-ATPase
}

\author{
Claudia 0. RODRIGUES, David A. SCOTT and Roberto DOCAMPO ${ }^{1}$ \\ Laboratory of Molecular Parasitology, Department of Pathobiology, College of Veterinary Medicine, University of Illinois at Urbana-Champaign, \\ 2001 South Lincoln Avenue, Urbana, IL 61802, U.S.A.
}

Inorganic pyrophosphate promoted the acidification of an intracellular compartment in permeabilized promastigotes of Leishmania donovani, as measured by Acridine Orange uptake. The proton gradient generated by pyrophosphate was collapsed by addition of nigericin or $\mathrm{NH}_{4} \mathrm{Cl}$. Pyrophosphate-driven proton translocation was stimulated by potassium ions, and inhibited by $\mathrm{NaF}$, the pyrophosphate analogues imidodiphosphate and aminomethylenediphosphonate (AMDP), dicyclohexylcarbodiimide, and the thiol reagents $p$-hydroxymercuribenzoate and $\mathrm{N}$ ethylmaleimide, all at concentrations similar to those that inhibit the plant vacuolar proton-pumping pyrophosphatase $\left(\mathrm{H}^{+}-\right.$ PPase). The proton translocation activity had a $\mathrm{pH}$ optimum in the range 7.0-7.5, and was unaffected by bafilomycin $A_{1}(40 \mathrm{nM})$, concanamycin A $(5 \mathrm{nM})$, sodium $o$-vanadate $(500 \mu \mathrm{M})$ and $\mathrm{KNO}_{3}(200 \mathrm{mM})$. AMDP-sensitive pyrophosphate hydrolysis was also detected in promastigotes, and potassium ions also stimulated this activity. Sodium ions disrupted $\mathrm{pH}$ gradients established in the presence of ATP but not in the presence of pyrophosphate, and sequential addition of ATP and pyrophosphate resulted in partially additive Acridine Orange accumulation, suggesting that the vacuolar $\mathrm{H}^{+}$-PPase is in a different intracellular compartment from the vacuolar $\mathrm{H}^{+}$ATPase and $\mathrm{Na}^{+} / \mathrm{H}^{+}$exchanger of $L$. donovani promastigotes. Separation of promastigote extracts on Percoll gradients yielded a dense fraction that contained $\mathrm{H}^{+}$-PPase activity but lacked ATPase activity and markers for mitochondria, glycosomes and lysosomes. The organelles in this fraction appeared by electron microscopy to consist of electron-dense vacuoles. In summary, these results indicate that, in contrast to plant vacuoles, vacuolar $\mathrm{H}^{+}$-PPase and vacuolar ATPase activities are present in different compartments in $L$. donovani promastigotes.

Key words: acidocalcisome, calcium, $\mathrm{Na}^{+} / \mathrm{H}^{+}$exchanger, X-ray microanalysis.

\section{INTRODUCTION}

Leishmania are dimorphic parasitic protozoa that live as flagellated promastigotes in the digestive tract of their insect vectors and as non-flagellated amastigotes in the phagolysosomes of mammalian macrophages. Like other trypanosomatids [1-5], Leishmania mexicana amazonensis has been shown to contain acidocalcisomes [6], novel organelles characterized by their acidity and high $\mathrm{Ca}^{2+}$ content. Acidocalcisomes are also present in apicomplexan parasites [7,8]. Recent studies [9-11] have indicated that these organelles are different from lysosomes or from any subcellular compartment previously characterized and that they correspond to 'inclusion vacuoles' $[12,13]$, or electrondense vacuoles [14,15], described morphologically in different trypanosomatids. In addition to calcium, these vacuoles have been shown, in Trypanosoma spp. [9,12-14] and in L. major [15], to contain high concentrations of phosphorus, magnesium, sodium and zinc.

A vacuolar proton-pumping pyrophosphatase (V-H $\mathrm{H}^{+}$-PPase) has been found in acidocalcisomes of Trypanosoma cruzi [11]. Such V-H $\mathrm{H}^{+}$-PPases have been identified in the energy-coupling membranes of plant vacuoles (tonoplasts) and in chromatophores of phototrophic bacteria [16]. A surprising feature of plant cells is the presence of a $\mathrm{V}-\mathrm{H}^{+}$-PPase and a vacuolar proton-pumping ATPase (V-H ${ }^{+}$-ATPase) in the same vacuolar membrane [16]. Why there are two different pumps acting to acidify the same organelle is not fully understood but, in at least some instances, the $\mathrm{V}-\mathrm{H}^{+}$-PPase is developmentally regulated [17], and its ex- pression is increased in response to anaerobiosis [18], as are other pyrophosphate-dependent enzymes that have ATP-utilizing analogues within the plant cell [19].

In the present study, we sought first to confirm that promastigotes of $L$. donovani, the aetiological agent of human visceral leishmaniasis, possess a $\mathrm{V}-\mathrm{H}^{+}$-PPase with features in common with the T. cruzi and plant activities. Secondly, we wished to study its subcellular location in comparison with the $\mathrm{V}-\mathrm{H}^{+}$-ATPase. We found that, in contrast to plants, the two activities reside in different compartments.

\section{MATERIALS AND METHODS}

\section{Culture methods}

L. donovani promastigotes (S-2 strain) were grown at $28{ }^{\circ} \mathrm{C}$ in medium SDM-79 [20] supplemented with haemin $(7.5 \mathrm{mg} / \mathrm{l})$ and $10 \%$ heat-inactivated fetal calf serum. After inoculation (2-3 days), cells were collected by centrifugation, washed twice in $0.25 \mathrm{M}$ sucrose, and resuspended in the same solution. Protein was measured using the Bio-Rad Coomassie Blue method.

\section{Chemicals}

Aprotinin, digitonin, imidodiphosphate, leupeptin, $N, N^{\prime}$-dicyclohexylcarbodiimide (DCCD), nigericin, pepstatin, $p$-hydroxymercuribenzoate, PMSF, $N$-ethylmaleimide and sodium ortho-

Abbreviations used: $\mathrm{V}-\mathrm{H}^{+}-\mathrm{PPase}$, vacuolar proton-pumping pyrophosphatase; $\mathrm{V}-\mathrm{H}^{+}$-ATPase, vacuolar proton-pumping ATPase; DCCD,

$N, N^{\prime}$-dicyclohexylcarbodiimide; AMDP, aminomethylenediphosphonate; FCCP, carbonyl cyanide p-trifluoromethoxyphenylhydrazone.

1 To whom correspondence should be addressed (e-mail rodoc@uiuc.edu). 


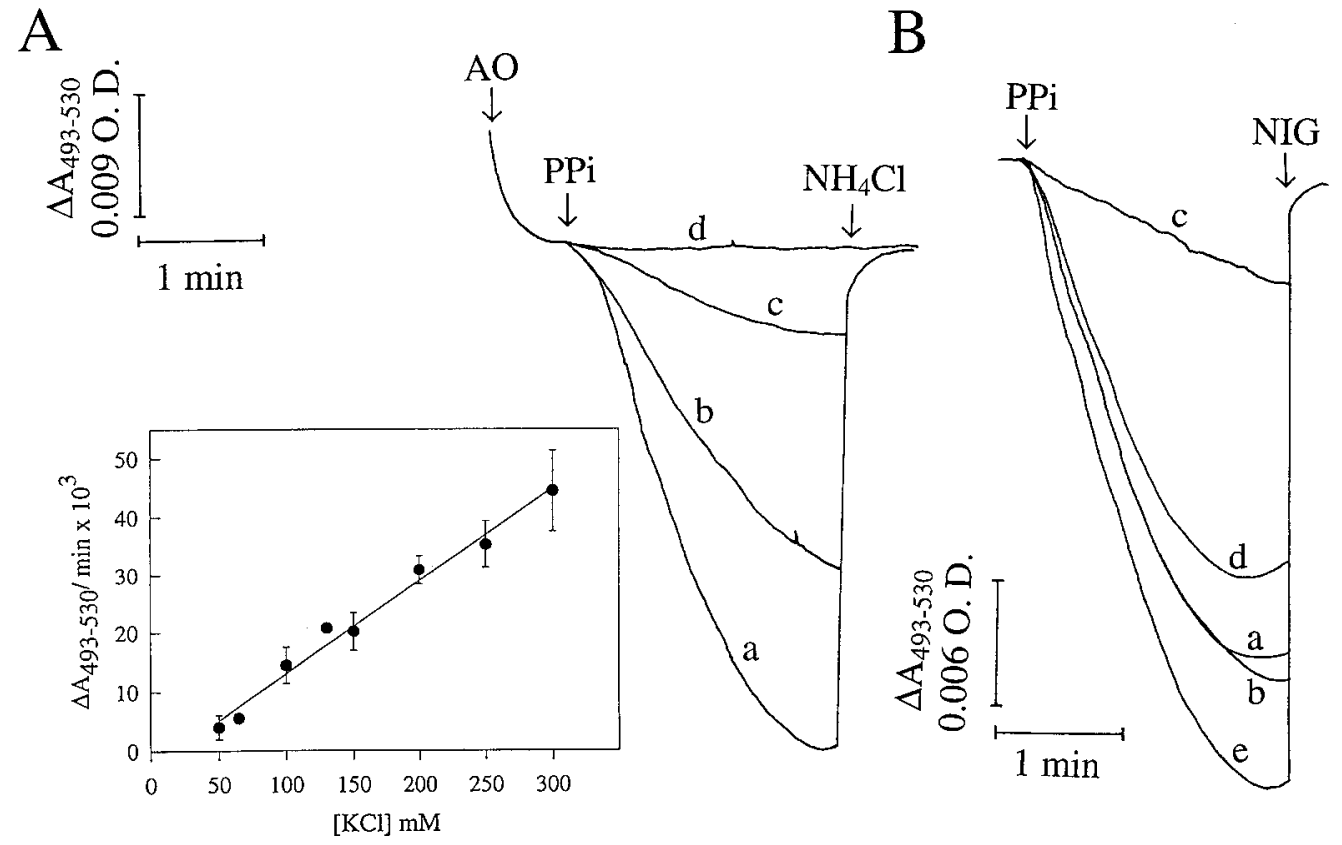

\section{Figure 1 Pyrophosphate-driven proton transport in permeabilized promastigotes}

All buffers contained $2 \mathrm{mM} \mathrm{MgSO}$, $50 \mu \mathrm{M}$ EGTA, $10 \mathrm{mM}$ Hepes (pH 7.2), $3 \mu \mathrm{M}$ Acridine Orange and $16 \mu \mathrm{M}$ digitonin. (A) Promastigotes ( $0.24 \mathrm{mg}$ of protein/ml) were added to buffer containing, in addition, $200 \mathrm{mM} \mathrm{KCl}$ (trace a), $130 \mathrm{mM} \mathrm{KCl}$ (trace b), $65 \mathrm{mM} \mathrm{KCl}$ and $125 \mathrm{mM}$ sucrose (trace c), or $125 \mathrm{mM}$ sucrose (trace d). Pyrophosphate (PPi, $0.1 \mathrm{mM}$ ) and $10 \mathrm{mM} \mathrm{NH}{ }_{4} \mathrm{Cl}$ were added where indicated. (B) Promastigotes ( $0.24 \mathrm{mg}$ of protein/ml) were added to the buffer containing, in addition, $200 \mathrm{mM} \mathrm{KCl}$ (trace a), $200 \mathrm{mM} \mathrm{KCl}$ and $65 \mathrm{mM} \mathrm{NaCl}$ (trace b), $200 \mathrm{mM} \mathrm{KCl}$ and $130 \mathrm{mM} \mathrm{NaCl}$ (trace C), $200 \mathrm{mM} \mathrm{KCl}$ and $65 \mathrm{mM}$ choline chloride (trace d) and $200 \mathrm{mM} \mathrm{KCl}$ and $130 \mathrm{mM}$ choline chloride (trace e). PP. $(0.1 \mathrm{mM})$ and $5 \mu \mathrm{M}$ nigericin (NIG) were added where indicated. $\mathrm{NH}_{4} \mathrm{Cl}(\mathbf{A})$ and $\mathrm{NIG}(\mathbf{B})$ were added for all traces but only one line is indicated for clarity since traces were superimposable. Inset shows the dependence of the initial acidification rate on $\mathrm{KCl}$ concentration, measured as in (A). Error bars indicate S.E. of means from at least three separate experiments.

vanadate were purchased from Sigma Chemical Co., St. Louis, MO, U.S.A. Dulbecco's PBS was from Gibco-BRL Life Technologies, Grand Island, NY, U.S.A. Bafilomycin $\mathrm{A}_{1}$ and concanamycin A were from Kamiya Biomedical, Thousand Oaks, CA, U.S.A. Acridine Orange, 2-amino-6-mercapto-7-methylpurine ribonucleoside, purine nucleoside phosphorylase and the standard phosphate solution were from Molecular Probes, Eugene, OR, U.S.A. Aminomethylenediphosphonate (AMDP) [21] was kindly provided by Professor Philip Rea, University of Pennsylvania. All other reagents were analytical grade.

\section{Pyrophosphate-linked proton-pump activity}

Pyrophosphate-driven vacuole acidification was assayed by measuring changes in the absorbance of Acridine Orange $\left(A_{493-530}\right)$ in an SLM-Aminco DW 2000 dual-wavelength spectrophotometer [11]. Cells $(0.6 \mathrm{mg}$ of protein) were incubated at $30{ }^{\circ} \mathrm{C}$ in $2.5 \mathrm{ml}$ of different buffers, as described in the Figures and Table (see below), plus Acridine Orange $(3 \mu \mathrm{M})$ and digitonin $(16 \mu \mathrm{M})$ for $3 \mathrm{~min}$ prior to the addition of $0.1 \mathrm{mM}$ sodium pyrophosphate $(\mathrm{pH}$ 7.2) unless indicated. Each experiment was repeated at least three times with different cell preparations, and the Figures show representative experiments.

\section{Pyrophosphatase assay}

Pyrophosphatase, as measured by released phosphate, was assayed as before [11], or else with the same assay, but with a volume of $0.1 \mathrm{ml}$ in a microtitre plate and single-wavelength (360 nm [22]) detection using a Bio-tek PowerWave 340 microplate scanning spectrophotometer (Bio-tek Instruments, Winooski, VT, U.S.A.). Rates shown in Table 1 (see below) are relative ( $\%)$ to AMDP $(20 \mu \mathrm{M})$-sensitive activity in the $200 \mathrm{mM}$ $\mathrm{KCl}$ buffer. Membranes were prepared by lysing cells by sonication in a buffer containing $125 \mathrm{mM}$ sucrose, $20 \mathrm{mM}$ Tris/Hepes ( $\mathrm{pH} 7.4)$ and protease inhibitors $(1 \mu \mathrm{g} / \mathrm{ml}$ leupeptin/ $1 \mu \mathrm{g} / \mathrm{ml}$ pepstatin $/ 1 \mu \mathrm{g} / \mathrm{ml}$ aprotinin/1 mM PMSF), followed by three washes $(2 \mathrm{~min}$ each at $2800 \mathrm{~g}$ ) and final resuspension of the membrane pellet in $0.25 \mathrm{M}$ sucrose.

\section{Subcellular fractionation}

Subcellular fractionation was performed as described previously [11]. Collected fractions were assayed for proton transport by pyrophosphate, ATPase activity and markers of mitochondria (succinate cytochrome $c$ reductase), glycosomes (hexokinase) and microsomes (acid phosphatase). ATPase activity was detected by measuring the decrease in absorbance of NADH in a coupled enzyme assay at $30^{\circ} \mathrm{C}$. A sample $(2.5-5 \mu \mathrm{l})$ was mixed with $100 \mu \mathrm{l}$ of reaction mixture containing $200 \mathrm{mM} \mathrm{KCl}, 4 \mathrm{mM}$ $\mathrm{MgCl}_{2}, 10 \mathrm{mM}$ EGTA, $1 \mathrm{mM}$ phosphoenolpyruvate, $5 \mathrm{mM}$ ATP, 14 units/ml pyruvate kinase, 20 units/ml lactate dehydrogenase, $0.3 \mathrm{mM}$ NADH and $30 \mathrm{mM}$ Hepes (pH 6.8 or 7.6). Marker enzymes were assayed as described previously [11], except that, for hexokinase and succinate cytochrome $c$ reductase, assay volumes were reduced 10-fold. All assays, except for proton transport, were performed using a PowerWave 340 plate reader (Bio-Tek Instruments).

\section{Electron microscopy}

For observation of Percoll fraction 1, the fraction was washed in $0.25 \mathrm{M}$ sucrose, and a 5- $\mu 1$ sample was placed on a Formvarcoated copper or nickel grid, allowed to adsorb for 5-15 min at 
room temperature, blotted dry and observed directly by electron microscopy [9]. Whole promastigotes were applied to grids in a similar manner [9]. Energy-dispersive X-ray analysis was done at the Electron Microscopy Center, Southern Illinois University [11]. Specimen grids were examined in a Hitachi H-7100FA transmission electron microscope at an accelerating voltage of $50 \mathrm{kV}$. Fine probe sizes were adjusted to cover the electron-dense granules (or similar area of background) and X-rays were collected for $100 \mathrm{~s}$ utilizing a thin-window $\left(\right.$ Norvar $\left.^{\mathbb{B}}\right)$ detector. Analysis was performed using a Noran Voyager III analyser with a standardless analysis identification program.

\section{RESULTS}

The formation of a pyrophosphate-dependent proton gradient (inside positive) in organelles in digitonin-permeabilized promastigotes of $L$. donovani was followed by the decrease in absorbance of Acridine Orange at 493-530 nm (Figure 1). This gradient was collapsed completely by the addition of $10 \mathrm{mM}$ $\mathrm{NH}_{4} \mathrm{Cl}$ (Figure 1A) or $5 \mu \mathrm{M}$ nigericin (Figure 1B, NIG). This proton-translocating activity showed a linear dependence on the concentration of $\mathrm{K}^{+}$up to $300 \mathrm{mM}$ (Figure 1A, and inset). Variation of pyrophosphate concentration between 0 and $0.5 \mathrm{mM}$ yielded maximal activity at $0.05-0.1 \mathrm{mM}$ (results not shown). $\mathrm{KCl}$ at $200 \mathrm{mM}$ and pyrophosphate at $0.1 \mathrm{mM}$ were used in subsequent experiments. Interestingly, a high $\mathrm{KCl}$ concentration was also needed for proton translocation by pumpkin hypocotyl tissue vacuolar pyrophosphatase reconstituted into proteoliposomes [23]. Proton-pumping activity could not be detected in the absence of added $\mathrm{K}^{+}$(Figure $1 \mathrm{~A}$, trace $\mathrm{d}$ and Table 1). Addition of $130 \mathrm{mM} \mathrm{NaCl}$ to the buffer (Figure 1B, trace $\mathrm{c}$ and Table 1) reduced the acidification rate. Addition of equimolar choline chloride $(130 \mathrm{mM})$ in the absence of isotonic correction did not significantly change the acidification rate (Figure $1 \mathrm{~B}$, trace $\mathrm{e}$ and Table 1) as compared with the rate in the presence of $200 \mathrm{mM} \mathrm{KCl}$ alone (Figure 1B, trace a and Table 1), indicating that the inhibition by $\mathrm{NaCl}$ was not due to changes in osmotic

Table 1 Effect of buffer composition on proton translocation and pyrophosphatase activity in $L$. donovani promastigotes

Acidification rate and pyrophosphatase activity were assayed as described in the Materials and methods section. Rates are relative percentages compared with the $200 \mathrm{mM} \mathrm{KCl}$ buffer. In all cases, AMDP $(20 \mu \mathrm{M})$-sensitive rates are indicated. All buffers contained, in addition, $2 \mathrm{mM}$ $\mathrm{MgSO}_{4}, 10 \mathrm{mM}$ Hepes and $50 \mu \mathrm{M}$ EGTA, and were adjusted to $\mathrm{pH} 7.2$ with $\mathrm{NaOH}, \mathrm{KOH}$ or Tris base for $\mathrm{NaCl}, \mathrm{K}^{+}$salts and choline buffers, respectively. Values are means \pm S.E. from the number of experiments indicated in parentheses. Control activities were $30.9 \pm 2.5$ $\Delta A_{493-530} / \mathrm{min} \times 10^{3}$ for the acidification rate and $0.74 \pm 0.08$ and $0.26 \pm 0.05 \Delta A_{355-330} / \mathrm{min}$ per $\mathrm{mg}$ of protein $\times 10^{3}$ for the total and AMDP-sensitive pyrophosphatase activities, respectively. ND, not detectable

\begin{tabular}{lcl}
\hline Buffer & $\begin{array}{l}\text { Acidification rate } \\
\text { (\% of control) }\end{array}$ & $\begin{array}{l}\text { Pyrophosphatase activity } \\
\text { (\% of control) }\end{array}$ \\
\hline $200 \mathrm{mM} \mathrm{KCl}$ & $100(24)$ & $100(4)$ \\
$65 \mathrm{mM} \mathrm{KCl} / 125 \mathrm{mM}$ sucrose & $21.2 \pm 2.8(3)$ & $110 \pm 18(3)$ \\
$65 \mathrm{mM} \mathrm{NaCl} / 125 \mathrm{mM}$ sucrose & $\mathrm{ND}(3)$ & $10.2 \pm 2.9(3)$ \\
$130 \mathrm{mM} \mathrm{NaCl}$ & $\mathrm{ND}(3)$ & $15.2 \pm 1.9(3)$ \\
$65 \mathrm{mM} \mathrm{choline}$ chloride/125 mM sucrose & $\mathrm{ND}(4)$ & $\mathrm{ND}(4)$ \\
$200 \mathrm{mM} \mathrm{KCl} / 65 \mathrm{mM} \mathrm{NaCl}$ & $127.8 \pm 6.8(5)$ & $63.8 \pm 9.2(3)$ \\
$200 \mathrm{mM} \mathrm{KCl} / 130 \mathrm{mM} \mathrm{NaCl}$ & $14 \pm 2.3(5)$ & $10.2 \pm 2.9(3)$ \\
$200 \mathrm{mM} \mathrm{KCl} / 130 \mathrm{mM} \mathrm{choline}$ chloride & $114.5 \pm 10.7(3)$ & Not determined \\
$\mathrm{Potassium} \mathrm{gluconate}_{\mathrm{K}_{2} \mathrm{SO}_{4}}$ & $56.6 \pm 11.6(4)$ & Not determined \\
$\mathrm{KNO}_{3}$ & $52.9 \pm 3.0(3)$ & Not determined \\
$\mathrm{KHCO}_{3}$ & $86.2 \pm 8.7(3)$ & Not determined \\
& $5.6 \pm 3.0(3)$ & Not determined \\
& &
\end{tabular}
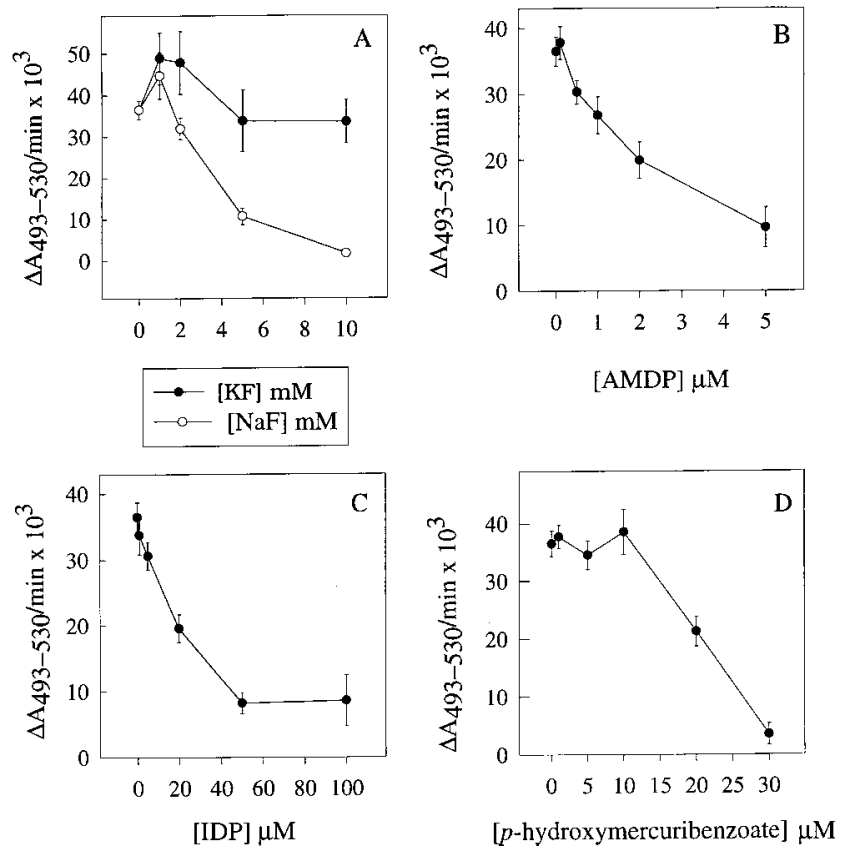

Figure 2 Inhibition of $\mathrm{V}-\mathrm{H}^{+}-\mathrm{PPase}$ activity in permeabilized promastigotes by KF (O), NaF (O), AMDP, imidodiphosphate (IDP) and p-hydroxymercuribenzoate

All assays were run in a buffer containing $200 \mathrm{mM} \mathrm{KCl}, 2 \mathrm{mM} \mathrm{MgSO}_{4}, 50 \mu \mathrm{M}$ EGTA, $10 \mathrm{mM}$ Hepes (pH 7.2), $3 \mu \mathrm{M}$ Acridine Orange, $16 \mu \mathrm{M}$ digitonin and promastigotes $(0.24 \mathrm{mg}$ of protein/ml). Promastigotes were incubated in the presence of inhibitors for $3 \mathrm{~min}$, during permeabilization, before addition of $0.1 \mathrm{mM}$ pyrophosphate. The results are indicated in $\Delta A_{493-530} / \mathrm{min} \times 10^{3}$. Error bars indicate S.E. of means from at least three separate experiments.
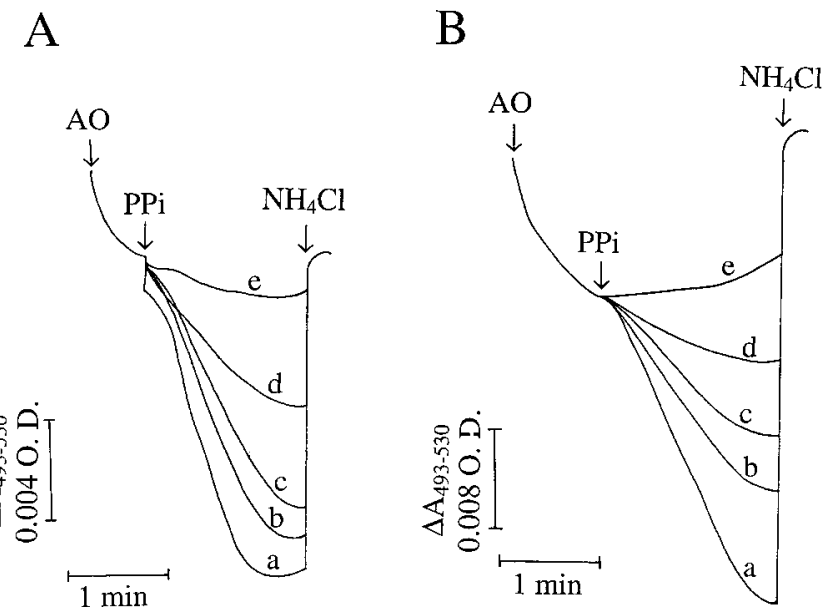

Figure 3 Inhibition by $N$-ethylmaleimide (A) and DCCD (B) of pyrophosphate-dependent proton uptake by permeabilized promastigotes

Promastigotes $(0.24 \mathrm{mg}$ of protein $/ \mathrm{ml})$ were preincubated for $10 \mathrm{~min}$ with $\mathrm{N}$-ethylmaleimide $(\mathbf{A})$ or 1 min with $\operatorname{DCCD}(\mathbf{B})$ in the buffer described in Figure 2, before addition of $0.1 \mathrm{mM}$ pyrophosphate (PPi). (A) Trace a, control without $\mathrm{N}$-ethylmaleimide; trace b, $50 \mu \mathrm{M}$; trace c, $100 \mu \mathrm{M}$; trace d, $200 \mu \mathrm{M}$; and trace e, $400 \mu \mathrm{M} N$-ethylmaleimide. (B) Trace a, control without DCCD; trace b, $100 \mu \mathrm{M}$; trace c, $150 \mu \mathrm{M}$; trace d, $250 \mu \mathrm{M}$; and trace e, $500 \mu \mathrm{M}$ DCCD. $\mathrm{NH}_{4} \mathrm{Cl}(10 \mathrm{mM})$ was added where indicated in all traces but only one line is shown for clarity since traces were superimposable. Abbreviation: A0, Acridine Orange. 


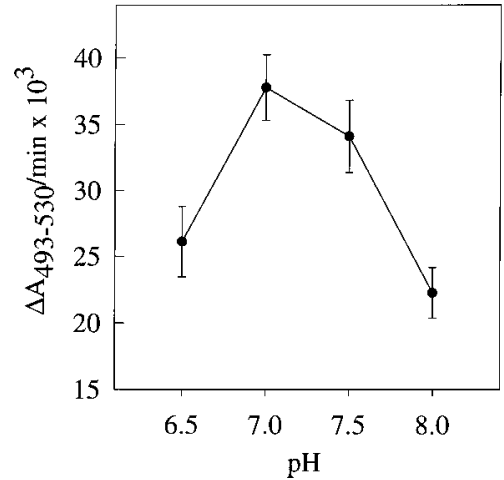

Figure 4 Initial rate of pyrophosphate-dependent proton uptake by permeabilized promastigotes as a function of medium $\mathrm{pH}$

Promastigotes $(0.24 \mathrm{mg}$ of protein $/ \mathrm{ml})$ were incubated in the same buffer described in Figure 2 adjusted to different pH values. The results are indicated in $\Delta A_{493-530} / \mathrm{min} \times 10^{3}$. Error bars indicate S.E. of means from at least three separate experiments.

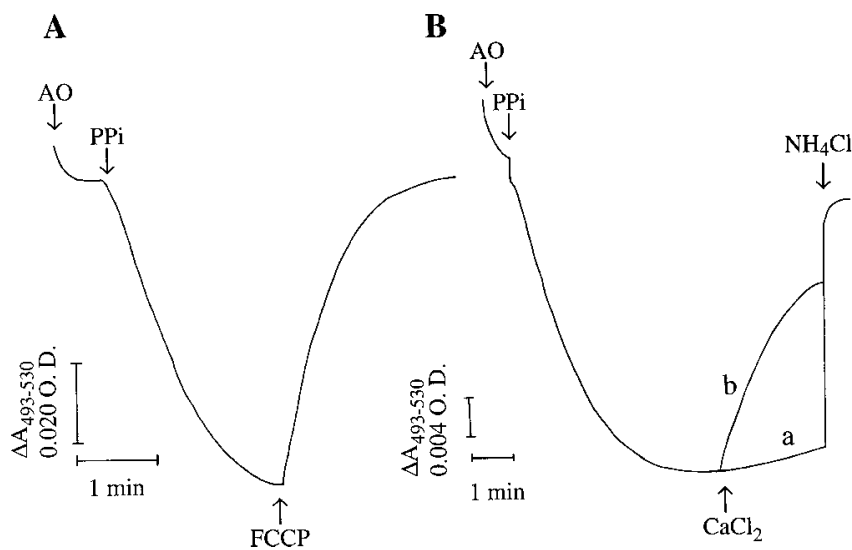

Figure 5 Effect of a protonophore (A) and $\mathrm{CaCl}_{2}$ (B) on pyrophosphatedependent proton uptake by permeabilized promastigotes

Experimental conditions were as in Figure 2. Acridine Orange ( $\mathrm{AO}, 3 \mu \mathrm{M})$, pyrophosphate (PPi, $0.5 \mathrm{mM})$, FCCP $(1 \mu \mathrm{M}), \mathrm{CaCl}_{2}(\mathbf{B}$, trace $\mathrm{b}, 100 \mu \mathrm{M})$, and $\mathrm{NH}_{4} \mathrm{Cl}(10 \mathrm{mM})$ were added where indicated. Trace a in $(\mathbf{B})$ is a control without $\mathrm{CaCl}_{2}$.

pressure. Altogether these data are in agreement with results obtained with plant $\mathrm{V}-\mathrm{H}^{+}$-PPases, which are largely $\mathrm{K}^{+}$dependent and inhibited by $\mathrm{Na}^{+}[16]$. This $\mathrm{K}^{+}$dependence differentiates $\mathrm{V}-\mathrm{H}^{+}$-PPases from known mitochondrial $\mathrm{H}^{+}$PPases, which do not require $\mathrm{K}^{+}$[24].

Pyrophosphate-induced acidification of permeabilized promastigotes was inhibited weakly by potassium fluoride and more markedly so, and in a dose-dependent manner, by sodium fluoride (Figure 2A). The pyrophosphate analogues AMDP (Figure 2B) and imidodiphosphate (Figure 2C), and the thiol reagent $p$-hydroxymercuribenzoate (Figure $2 \mathrm{D}$ ) were also inhibitory. The effective concentrations of $\mathrm{NaF}$, imidodiphosphate and AMDP were similar to those that inhibit plant $[25,26]$ and $T$. cruzi $[11] \mathrm{V}-\mathrm{H}^{+}$-PPase activities.

The effect of different known $\mathrm{H}^{+}$-ATPase inhibitors on pyrophosphate-dependent Acridine Orange uptake by permeabilized promastigotes was also investigated. Vanadate $\left(500 \mu \mathrm{M}\right.$, uptake rate $\left.29.7 \pm 1.9 \Delta A_{493-530} / \mathrm{min} \times 10^{3}\right)$, a P-type $\mathrm{H}^{+}$-ATPase inhibitor, bafilomycin $\mathrm{A}_{1} \quad(40 \mathrm{nM}, 29.7 \pm 1.9$

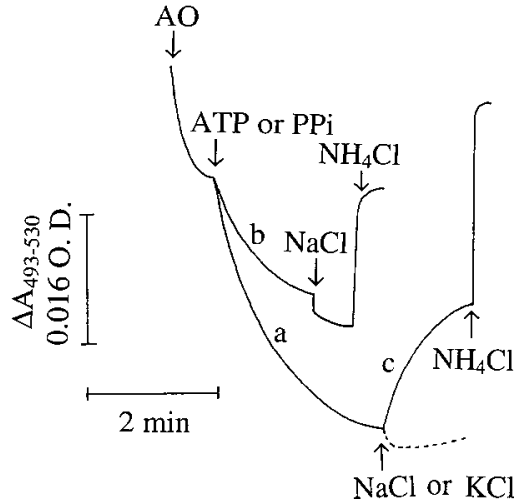

Figure 6 Effect of $\mathrm{NaCl}$ on ATP- and pyrophosphate-dependent proton transport in permeabilized promastigotes

Promastigotes $(0.24 \mathrm{mg}$ of protein $/ \mathrm{ml})$ were incubated in a buffer containing $130 \mathrm{mM} \mathrm{KCl}$,

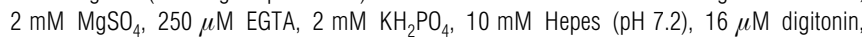
$1 \mu \mathrm{g} / \mathrm{ml}$ antimycin A and $2 \mu \mathrm{g} / \mathrm{ml}$ oligomycin. Acridine Orange (A0, $3 \mu \mathrm{M})$, ATP (1 mM, trace a), pyrophosphate (PPi, $0.5 \mathrm{mM}$, trace b), $\mathrm{NaCl}(40 \mathrm{mM}$, traces b and c), $\mathrm{KCl}(40 \mathrm{mM}$, dashed line) and $\mathrm{NH}_{4} \mathrm{Cl}(10 \mathrm{mM})$ were added where indicated.
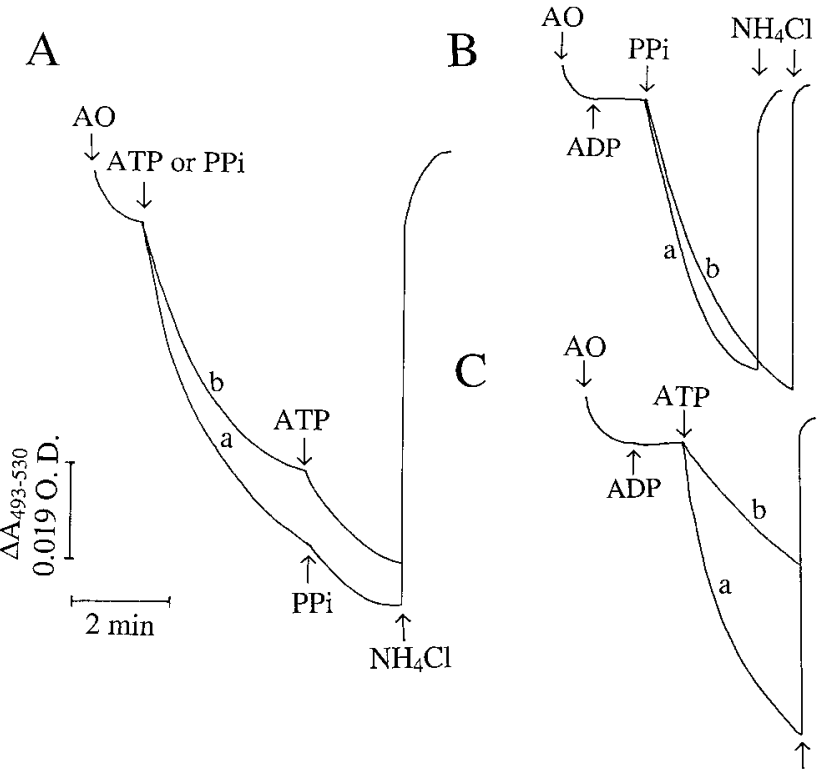

$\mathrm{NH}_{4} \mathrm{Cl}$

Figure 7 ATP- and pyrophosphate-dependent proton uptake by permeabilized promastigotes

Promastigotes $(0.24 \mathrm{mg}$ of protein/ $\mathrm{ml}$ ) were incubated in the same buffer as described in Figure 2. (A) ATP (1 mM) was added before (trace a) or after (trace b) pyrophosphate (PPi, $0.1 \mathrm{mM})$. (B) Promastigotes were incubated in the same buffer as in $(\mathbf{A})$ in the absence (trace a) or presence (trace b) of $1 \mathrm{mM} \mathrm{ADP} \mathrm{(added} \mathrm{where} \mathrm{indicated),} \mathrm{before} \mathrm{addition} \mathrm{of} \mathrm{pyrophosphate.}$ (C) Promastigotes were incubated in the same buffer as in $(\mathbf{A})$ in the absence (trace a) or presence (trace $b$ ) of $1 \mathrm{mM} \mathrm{ADP}$, before addition of ATP. Acridine Orange (A0, $3 \mu \mathrm{M})$, ADP $(1 \mathrm{mM})$, ATP $(1 \mathrm{mM})$, pyrophosphate $(0.1 \mathrm{mM})$, and $\mathrm{NH}_{4} \mathrm{Cl}(10 \mathrm{mM})$ were added where indicated. Only one line is indicated in some traces for clarity since they were superimposable.

$\left.\Delta A_{493-530} / \mathrm{min} \times 10^{3}\right)$ and concanamycin A $(5 \mathrm{nM}, 30.9 \pm 2.2$ $\left.\Delta A_{493-530} / \mathrm{min} \times 10^{3}\right)$, two specific $\mathrm{V}-\mathrm{H}^{+}$-ATPase inhibitors when used at nanomolar concentrations [27], were unable to significantly affect this activity (control rate: $30.9 \pm 2.5 \Delta A_{493-530} /$ $\left.\min \times 10^{3}\right)$. In contrast, the plant $\mathrm{V}-\mathrm{H}^{+}$-PPase inhibitors DCCD 

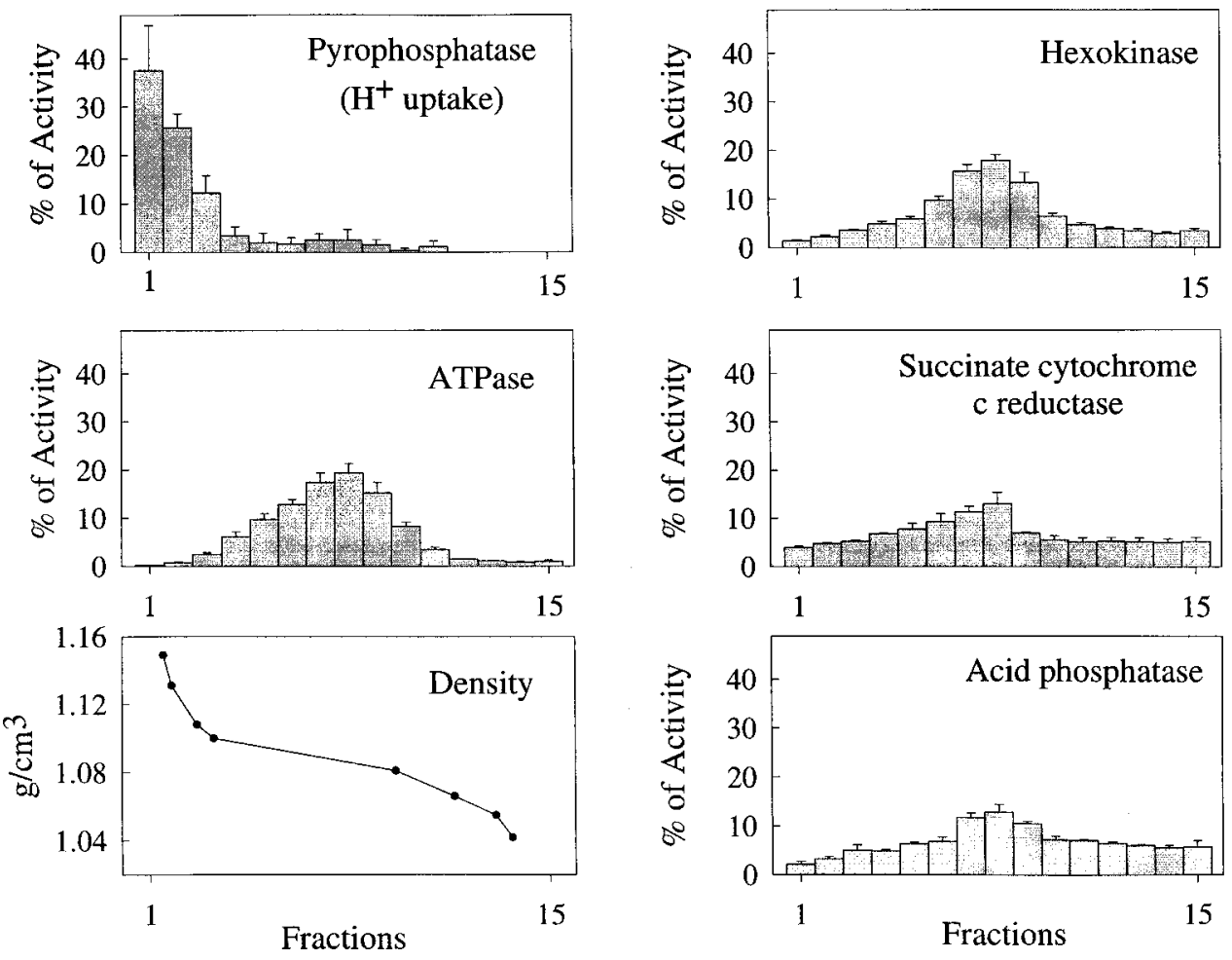

Figure 8 Distribution of PPase activity from $L$. donovani promastigotes on Percoll density gradients

PPase is concentrated in a distinct, dense fraction. V- $\mathrm{H}^{+}-$PPase activity measured by proton uptake was compared with the distribution of ATPase and established organelle markers: succinate cytochrome $c$ reductase (mitochondria), hexokinase (glycosome) and acid phosphatase (microsomal fraction). Histograms show activity (as percentage total recovered activity, means \pm S.E.M.) from three independent experiments. Density was measured in a single experiment using Percoll density-marker beads.

$[28,29]$ and $N$-ethylmaleimide $[30,31]$ had concentrationdependent inhibitory effects (Figures $3 \mathrm{~A}$ and $3 \mathrm{~B}$ ). Inhibition by $N$-ethylmaleimide was greater with 10 min compared with 5 or 1 min pre-incubation time (results not shown); pre-incubation was not extended further, as permeabilization of internal organelles by digitonin lowered control activity after prolonged treatment. Pre-incubation with DCCD for more than 1 min did not increase inhibition. Lower concentrations of DCCD $(50 \mu \mathrm{M})$ had no significant inhibitory effect (results not shown).

Pyrophosphatase was also assayed in membrane preparations of promastigotes by inorganic phosphate detection using purine nucleoside phosphorylase and 2-amino-6-mercapto-7-methylpurine as the substrate with phosphate $[11,22]$. AMDP $(20 \mu \mathrm{M})$ only inhibited total activity by $63 \pm 3.8 \%$ (mean \pm S.E. of four experiments). This could indicate the presence of other AMDPinsensitive pyrophosphatases, or non-specific phosphatase activities in these preparations. The effect of $\mathrm{NaCl}$ on AMDPinhibitable activity in promastigotes was in general similar to that found in the Acridine Orange assay (Table 1). Very low activity was detectable if $\mathrm{KCl}$ in the medium was replaced with $\mathrm{NaCl}$. However, the activity did not increase with increasing $\mathrm{KCl}$ concentration (Table 1), unlike proton translocation (Figure 1A, inset and Table 1). The reason for this discrepancy is not known. However, a similar discrepancy in the $\mathrm{K}^{+}$concentration-dependence of proton-translocating activity and pyrophosphate hydrolysis was observed in a preparation of purified plant $\mathrm{V}-\mathrm{H}^{+}-$ PPase reconstituted into proteoliposomes [23]. The specific activity in membrane preparations of promastigotes was $28 \pm 4 \mathrm{nmol}$ of pyrophosphate consumed/min per $\mathrm{mg}$ of protein (mean \pm S.E. of four separate experiments).
Figure 4 shows the effect of medium $\mathrm{pH}$ on the pyrophosphatedependent acidification rate in promastigotes: activity was optimal in the range $\mathrm{pH} 7.0-7.5$. Table 1 also shows that the acidification rate was not significantly affected when $\mathrm{NO}_{3}{ }^{-}$was used as the buffer anion instead of $\mathrm{Cl}^{-}$. However, this rate was inhibited when $\mathrm{SO}_{4}{ }^{2-}$, gluconate or, especially, $\mathrm{HCO}_{3}{ }^{-}$was used as the anion.

As occurs in some plant vacuoles [32], carbonyl cyanide p-trifluoromethoxyphenylhydrazone (FCCP) caused Acridine Orange release (Figure 5A), suggesting that the vacuoles containing the pyrophosphatase had an inside-positive membrane potential. Figure 5(B) shows that addition of $100 \mu \mathrm{M} \mathrm{CaCl}_{2}$ partially reversed the pyrophosphate-induced decrease in Acridine Orange absorbance. Addition of $10 \mathrm{mM} \mathrm{NH}_{4} \mathrm{Cl}$ completed this proton release. These results are consistent with the known inhibition of plant $\mathrm{V}-\mathrm{H}^{+}-\mathrm{PPase}$ activity by micromolar $\mathrm{Ca}^{2+}[33,34]$. Addition of $20 \mu \mathrm{M}$ AMDP at this point also led to a reversal of the Acridine Orange spectral change (results not shown).

$\mathrm{Na}^{+}$ions added to digitonin-permeabilized $T$. brucei procyclic trypomastigotes reduce ATP-generated proton gradients, suggesting the operation of an $\mathrm{Na}^{+} / \mathrm{H}^{+}$exchanger in these cells [4,5]. Evidence for a similar exchanger in $L$. donovani promastigotes has also been obtained (A. E. Vercesi, C. O. Rodrigues, and R. Docampo, unpublished work, and see below). We reasoned that co-localization of the $\mathrm{V}-\mathrm{H}^{+}$-ATPase and the $\mathrm{V}-\mathrm{H}^{+}$-PPase in L. donovani promastigotes might be demonstrated by comparing $\mathrm{Na}^{+}$-dependent proton efflux from (nonmitochondrial) compartments acidified previously with either ATP or pyrophosphate. L. donovani promastigotes were permeabilized first with digitonin in $\mathrm{Na}^{+}$-free medium in the 

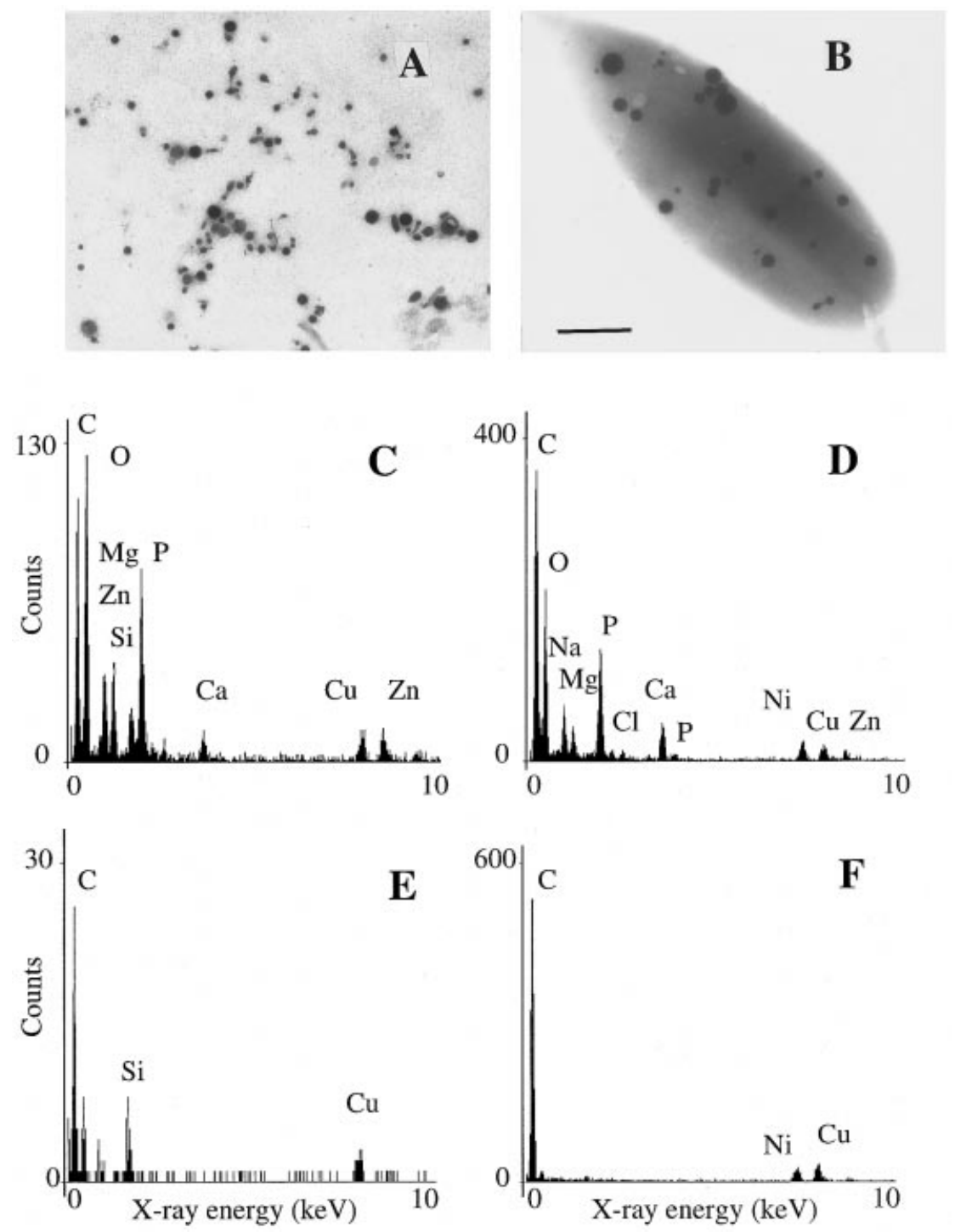

Figure 9 The dense PPase-containing fraction consists of acidocalcisomes

(A) Direct observation of Percoll fraction 1 by electron microscopy. (B) Whole promastigotes were treated similarly for comparison. Scale bar $=1 \mu \mathrm{m}$. (C) and (D) show typical X-ray microanalysis spectra of a dense organelle in an isolated fraction $(\mathbf{C})$ and in intact promastigotes $(\mathbf{D})$. $(\mathbf{E})$ and $(\mathbf{F})$ show background spectra of fraction $1(\mathbf{E})$ or the whole promastigote preparation $(\mathbf{F})$.

presence of mitochondrial inhibitors, and either ATP or pyrophosphate was added. Figure 6 (trace a) shows that, in agreement with the $T$. brucei results [4,5], ATP drives Acridine Orange accumulation by an intracellular compartment in permeabilized promastigotes. A partial release of Acridine Orange could be induced by the addition of $40 \mathrm{mM} \mathrm{NaCl}$ (Figure 6, trace c), but not by $40 \mathrm{mM} \mathrm{KCl}$ (Figure 6, dashed line), thus indicating that the effect was not due to changes in the osmotic pressure and that $\mathrm{Na}^{+}$was the active cation. Addition of 3,5-dibutyl-4-hydroxytoluene, an inhibitor of the T. brucei $\mathrm{Na}^{+} / \mathrm{H}^{+}$exchanger [5], reversed this $\mathrm{NaCl}$ effect (A. E. Vercesi, C. O. Rodrigues and R. Docampo, unpublished work). When Acridine Orange accumulation was driven by pyrophosphate instead of ATP, addition of either $40 \mathrm{mM} \mathrm{NaCl}$ (Figure 6, trace b), $40 \mathrm{mM} \mathrm{KCl}$ or $40 \mathrm{mM}$ choline chloride (results not shown) did not result in Acridine Orange efflux, but in a non-specific additional influx, suggesting that the compartment containing the $\mathrm{V}-\mathrm{H}^{+}-\mathrm{PPase}$ is different from the one containing the $\mathrm{V}-\mathrm{H}^{+}$-ATPase and the $\mathrm{Na}^{+} / \mathrm{H}^{+}$exchanger. Sequential addition of pyrophosphate and ATP resulted in a partially additive accumulation of Acridine Orange (Figure 7A). It has been claimed that ADP is a substrate for the $\mathrm{V}-\mathrm{H}^{+}$-PPase of pea stem [35]. Here, ADP was found to inhibit ATP-driven (Figure 7C), but not pyrophosphate-driven (Figure 7B), Acridine Orange accumulation.

To study the subcellular location of the $\mathrm{V}-\mathrm{H}^{+}-\mathrm{PPase}$, extracts of promastigotes were separated in Percoll gradients (Figure 8). The $\mathrm{V}-\mathrm{H}^{+}$-PPase, as assayed by Acridine Orange uptake, was concentrated towards the bottom (dense end) of the gradient (fraction 1), as found with T. cruzi [11]. Markers for other compartments and ATPase activity [either at pH 6.8 (Figure 8) or 7.6 (results not shown)] all peaked further up the gradient in the region of fractions 7-9. No proton-pumping ATPase activity was detected in fraction 1 (results not shown). The average amount of each organelle marker found in fraction 1 was under 
$5 \%$ of the total recovered activity of that marker, compared with $38 \%$ of $\mathrm{H}^{+}$-PPase activity. Examination of fraction 1 by electron microscopy showed round electron-dense organelles of variable size up to $200 \mu \mathrm{m}$ in diameter (Figure 9A). These were similar to dense organelles found in whole promastigotes (Figure 9B). Such organelles were previously identified as acidocalcisomes in $T$. cruzi $[9,11]$. To confirm this identification, X-ray microanalysis was performed on the fraction-1 preparation (Figure 9C). The spectrum shown was the one that yielded the most counts in $100 \mathrm{~s}$ (out of 10 spectra obtained), but all other spectra taken from dense organelles were qualitatively similar: counts for phosphorus were about 2-fold greater than counts for magnesium, which were about 3-fold greater than counts for calcium. Zinc was also present in several spectra. Spectra obtained from acidocalcisomes in whole promastigotes (Figure 9D) were similar to those taken from the isolated organelle (Figure 9C), except that more sodium and less zinc were detected. Peaks for calcium, phosphorus, magnesium and zinc were not present in a spectrum taken from the fraction-1 sample background (Figure 9E), or in the background from the whole-cell preparation (Figure 9F). Peaks for copper and nickel arise from the grid and silicon from traces of Percoll in the specimen.

\section{DISCUSSION}

In the present study, an $\mathrm{H}^{+}$-PPase activity has been characterized in permeabilized promastigotes of $L$. donovani. Acridine Orange uptake in the presence of pyrophosphate was reversed by the $\mathrm{K}^{+}\left(\mathrm{Na}^{+}\right) / \mathrm{H}^{+}$exchanger, nigericin or by alkalinization of the acidic compartment with $\mathrm{NH}_{4} \mathrm{Cl}$ (Figure 1). This proton-translocating activity was optimal at $\mathrm{pH} 7.0-7.5$ (Figure 4B). The $\mathrm{pH}$ optimum of PPase in tonoplast vesicles from red beet is between 7.5 and 8.0 [36].

Pyrophosphate-driven proton transport was blocked by NaF, by the pyrophosphate analogues imidodiphosphate and AMDP (Figure 2), reversed by protonophores and $\mathrm{CaCl}_{2}$ (Figure 5), stimulated by potassium ions and inhibited by sodium ions (Figure 1 and Table 1). All of these characteristics are similar to those of the plant $\mathrm{V}-\mathrm{H}^{+}$-PPase [16]. $\mathrm{Na}^{+}$and $\mathrm{F}^{-}$may have a synergistic effect that is not seen when both are added separately.

Reduced thiol groups were required for promastigote $\mathrm{V}-\mathrm{H}^{+}-$ PPase activity, as indicated by its sensitivity to $p$-hydroxymercuribenzoate (Figure 2D) and $N$-ethylmaleimide (Figure 3A). This is in contrast to the insensitivity to $N$-ethylmaleimide of the pyrophosphate-dependent proton transport of permeabilized procyclic trypomastigotes of T. brucei (C. O. Rodrigues, D. A. Scott, and R. Docampo, unpublished work). These different sensitivities may be due to the different accessibility of $N$ ethylmaleimide to cysteine residues in different $\mathrm{V}-\mathrm{H}^{+}$-PPases. Site-directed mutagenesis studies of plant vacuolar PPases [31] have suggested that there is no direct participation of any cysteine in the catalytic cycle of the enzyme. Rather, the inhibitory effect of maleimides was attributed to structural deformation imposed through the introduction of a bulky alkyl group at a non-catalytic site [31].

It has been argued that the plant vacuolar PPase transports $\mathrm{K}^{+}$ in addition to $\mathrm{H}^{+}$in intact vacuoles [37], although this has been disputed by others [32]. The increase in proton translocation with higher $\mathrm{KCl}$ concentrations without any change in pyrophosphate hydrolytic activity (Table 1 ) would argue against $\mathrm{K}^{+}$translocation by the $L$. donovani $\mathrm{V}-\mathrm{H}^{+}-\mathrm{PPase}$, since if that were the case, increasing $\mathrm{K}^{+}$concentration would compete with $\mathrm{H}^{+}$ions for a common translocation site, as suggested previously in plant vacuoles [37]. As proposed for plant vacuoles [32], the stimulation of $\mathrm{V}-\mathrm{H}^{+}$-PPase activity by $\mathrm{K}^{+}$may reflect some structural requirements for this, the major cationic species in the cytosol.

The $\mathrm{V}-\mathrm{H}^{+}$-PPase was insensitive to bafilomycin $\mathrm{A}_{1}$ and concanamycin A, two specific inhibitors of $\mathrm{V}-\mathrm{H}^{+}$-ATPases [27], and to sodium $o$-vanadate, a general P-type ATPase inhibitor. Like the plant vacuolar PPase, the proton-translocating activity required a permeant anion (Table 1 ), and was not inhibited by $\mathrm{NO}_{3}{ }^{-}$, as are $\mathrm{V}-\mathrm{H}^{+}$-ATPases [38]. In contrast, $\mathrm{HCO}_{3}{ }^{-}$was a potent inhibitor of Acridine Orange uptake. This could reflect $\mathrm{HCO}_{3}^{-} / \mathrm{K}^{+}$co-transport into the acidic compartment, rendering it more alkaline. In contrast to pea stem tonoplast-enriched vesicles [35], ADP was not an effective substrate for proton transport in permeabilized promastigotes (Figure 7B).

Our results using permeabilized cells (Figures 6 and 7) suggested that ATP- and pyrophosphate-dependent protonpumping activities are, at least in part, located in different vacuolar membranes in $L$. donovani, in contrast to the plant tonoplast [16]. This was confirmed by subcellular fractionation of extracts of $L$. donovani promastigotes (Figure 8). Most of the pyrophosphatase activity was present in the densest fractions, separate from the location of established organelle markers and the bulk of the total ATPase activity of the cells. Electron microscopy of the densest fraction from the Percoll gradient showed that it contained electron-dense organelles (Figure 9A) similar to the acidocalcisomes described in T. cruzi $[9,11]$. X-ray microanalysis of these organelles yielded spectra with peaks indicating phosphorus, magnesium, calcium and zinc (Figure 9C), a typical elemental composition of acidocalcisomes $[9,11]$. Interestingly, a line attributed to sodium was detected in the whole cells and this was replaced by a line attributed to zinc in the isolated acidocalcisomes. Sodium has a main peak at $1.041 \mathrm{kV}$ (K $\alpha$ line), whereas zinc has a secondary peak at $1.034 \mathrm{kV}(\mathrm{L} \beta 1$ line) and another one at 1.012 ( $\mathrm{L} \alpha 1$ line). All three peaks are so close that they may merge into one broad peak and be identified as sodium in whole cells. The sodium might have been removed during fractionation leaving behind the zinc, which was then more readily detected. Previous experiments using L. mexicana amazonensis [6] have indicated the presence of a bafilomycin $\mathrm{A}_{1}$ sensitive $\mathrm{Ca}^{2+}$ pool in these cells. Our present results suggest the presence of different acidic calcium pools (acidocalcisomes) in these parasites that could use different proton pumps for their acidification.

Inorganic pyrophosphate is a by-product of several biosynthetic reactions (synthesis of nucleic acids, coenzymes and proteins, activation of fatty acids) and, in many cell types, soluble pyrophosphatases are required to hydrolyse pyrophosphate to make these reactions thermodynamically possible. It has been calculated that the pyrophosphate concentration in promastigotes of $L$. major is about $11 \mathrm{mM}$ and it was shown that this level increased about 1.4-fold under anaerobic conditions and in the absence of a useable carbon source [39]. However, the location of pyrophosphate in these parasites was not determined. If soluble pyrophosphatases are not present in $L$. donovani promastigotes, the $\mathrm{V}-\mathrm{H}^{+}$-PPase may serve to degrade cytosolic pyrophosphate, as it must do in photosynthetic plant tissues that lack soluble cytosolic pyrophosphatases [16]. Additionally, concomitantly occurring proton transport may be involved in the $\mathrm{pH}$ regulation of the cytoplasm and intracellular compartments, as suggested for the $\mathrm{H}^{+}$-ATPase in other trypanosomatids [40,41]. Whatever the role of the $\mathrm{V}-\mathrm{H}^{+}-\mathrm{PPase}$, the absence of a similar enzyme in the mammalian host makes it an attractive target for novel anti-trypanosomatid chemotherapy.

We thank Philip A. Rea and Yolanda M. Drozdowicz for the gift of aminomethylenediphosphonate and Mauro Sola Penna and John Bozzola for useful discussions. 
This work was supported by a grant from the National Institutes of Health (Al-23259) to R.D. C.O.R. was a fellow of the Conselho Nacional de Desenvolvimento Científico e Tecnológico (CNPq), Brazil.

\section{REFERENCES}

1 Vercesi, A. E., Moreno, S. N. J. and Docampo, R. (1994) Biochem. J. 304, 227-233

2 Scott, D. A., Moreno, S. N. J. and Docampo, R. (1995) Biochem. J. 310, 789-794

3 Docampo, R., Scott, D. A., Vercesi, A. E. and Moreno, S. N. J. (1995) Biochem. J. 310, 1005-1012

4 Vercesi, A. E. and Docampo, R. (1996) Biochem. J. 315, 265-270

5 Vercesi, A. E., Grijalba, M. and Docampo, R. (1997) Biochem. J. 328, 479-482

6 Lu, H.-G., Zhong, L., Chang, K.-P. and Docampo, R. (1997) J. Biol. Chem. 272 , 9464-9473

7 Moreno, S. N. J. and Zhong, L. (1996) Biochem. J. 313, 655-659

8 Garcia, R. S., Ann, S.E., Tavares, E. S., Dluzewski, A. R., Mason, W. T. and Paiva, F. B. (1998) Eur. J. Cell Biol. 76, 133-138

9 Scott, D. A., Docampo, R., Dvorak, J. A., Shi, S. and Leapman, R. D. (1997) J. Biol. Chem. 272, 28020-28029

10 Lu, H.-G., Zhong, L., de Souza, W., Benchimol, M., Moreno, S. N. J. and Docampo, R. (1998) Mol. Cell. Biol. 18, 2309-2323

11 Scott, D. A., de Souza, W., Benchimol, M., Zhong, L., Lu, H.-G., Moreno, S. N. J. and Docampo, R. (1998) J. Biol. Chem. 273, 22151-22158

12 Vickerman, K. and Tetley, L. (1977) Ann. Soc. Belge Med. Trop. 57, 441-455

13 Williamson, J. and McLaren, D. J. (1981) J. Protozool. 28, 460-467

14 Dvorak, J. A., Engel, J. C., Leapman, R. D., Swyt, C. R. and Pella, P. A. (1988) Mol. Biochem. Parasitol. 31, 19-26

15 LeFurgey, A., Ingram, P. and Blum, J. J. (1990) Mol. Biochem. Parasitol. 40, 77-86

16 Rea, P. A. and Poole, R. J. (1993) Annu. Rev. Plant Physiol. Plant Mol. Biol. 44, $157-180$

17 Nakanishi, Y. and Maeshima, M. (1998) Plant Physiol. 116, 589-597
18 Carystinos, G. D. MacDonald, H. R., Monroy, A. F., Dhindsa, R. S. and Poole, R. J. (1995) Plant Physiol. 108, 641-649

19 Stitt, M. (1998) Bot. Acta 111, 167-175

20 Brun, R. and Schönenberg, M. (1979) Acta Trop. 36, 289-292

21 Zhen, R.-G., Baykov, A. A., Bakuleva, N. P. and Rea, P. A. (1994) Plant Physiol. 104, 153-159

22 Webb, M. R. (1992) Proc. Natl. Acad. Sci. U.S.A. 89, 4884-4887

23 Sato, M. J., Kasahara, M., Ishii, N., Homareda, H., Matsui, H. and Yoshida, M. (1994) J. Biol. Chem. 269, 6725-6728

24 Lundin, M., Deopujari, S. W., Lichko, L., Pereira da Silva, L. and Baltscheffsky, H. (1992) Biochim. Biophys. Acta 1098, 217-223

25 Wang, Y., Leigh, R. A., Kaestner, K. H. and Sze, H. (1986) Plant Physiol. 81, 497-502

26 Zhen, R.-G., Baykov, A. A., Bakuleva, N. P. and Rea, P. A. (1994) Plant Physiol. 104, $153-159$

27 Dröse, S. and Altendorf, K. (1997) J. Exp. Biol. 200, 1-8

28 Maeshima, M. and Yoshida, S. (1989) J. Biol. Chem. 264, 20068-20073

29 Zhen, R.-G., Kim, E. J. and Rea, P. A. (1997) J. Biol. Chem. 272, 22340-22348

30 Zhen, R.-G., Kim, E. J. and Rea, P. A. (1994) J. Biol. Chem. 269, 23342-23350

31 Kim, E. J., Zhen, R.-G. and Rea, P. A. (1995) J. Biol. Chem. 270, 2630-2635

32 Ros, R., Romieu, C., Gibrat, R. and Grignon, C. (1995) J. Biol. Chem. 270 4368-4374

33 Maeshima, M. (1991) Eur. J. Biochem. 196, 11-17

34 Rea, P. A., Britten, C. J., Jennings, I. R., Calvert, C. and Sanders, D. (1992) Plant Physiol. 100, 1706-1715

35 Macri, F. and Vianello, A. (1987) FEBS Lett. 215, 47-52

36 Rea, P. A. and Poole, R. J. (1985) Plant Physiol. 77, 46-52

37 Davies, J. M., Poole, R. J., Rea, P. A. and Sanders, D. (1992) Proc. Natl. Acad. Sci. U.S.A. 89, 11701-11705

38 Finbow, M. E. and Harrison, M. A. (1997) Biochem. J. 324, 697-712

39 Blum, J. J. (1989) J. Protozool. 36, 254-257

40 Benchimol, M., de Souza, W., Zhong, L., Lu, H.-G., Moreno, S. N. J. and Docampo, R. (1998) Biochem. J. 332, 695-702

41 Scott, D. A. and Docampo, R. (1998) Biochem. J. 331, 583-589

Received 24 August 1998/8 March 1999; accepted 1 April 1999 